\title{
SPREAD OF GORSE AND BROOM SEED BY ANIMALS
}

\author{
N.LEDGARD ${ }^{1}$ and D. ROSSITER ${ }^{2}$ \\ ${ }^{1}$ NZ Forest Research Institute, 57 Oxford Road, Rangiora \\ ${ }^{2} 7$ Rex Place, Rangiora
}

Animals, particularly sheep, are probably major carriers of gorse and broom seed in New Zealand. It is likely that they have been responsible in the past for gorse and broom invasion of significant areas of clean country. The process may well be continuing today virtually unchecked. Case studies are described and simple strategies proposed to minimise the risk of spread by animals. Land managers and administrators need to be alerted to spread risks involving animals, in particular to grazing sheep in gorse / broom areas during times of seed pod explosion and then moving them to clean country before they are shorn. Birds are often accused of spreading seed, but there is no New Zealand documentation to support this. Research is required to define more precisely the role that birds and animals (such as sheep, cattle, goats, deer and pigs) play in spreading gorse and broom.

\section{RESISTANCE OF SLENDER WINGED THISTLE TO MCPA}

\author{
K.C. HARRINGTON and N. HEWAGE \\ Department of Plant Science, Massey University, Private Bag 11-222, Palmerston North
}

Resistance to MCPA and 2.4-D has been detected and confirmed in nodding thistle (Carduus nutans) at several sites in Hawke's Bay and Waikato. A resistant ecotype of slender winged thistle (Carduus pycnocephalus) has also been suspected at one of these Hawke's Bay sites. Previous glasshouse studies have shown that the slender winged thistle plants were as resistant to MCPA as resistant nodding thistle plants. DowElanco field trials have shown slender winged thistle at this site requires eight times the standard application rate of 2,4-D to obtain satisfactory control. However, as slender winged thistle is considered by some to be difficult to control normally, further work was required to confirm that resistance exists. Three lots of slender winged thistle seed were collected from: 1) plants flowering at the suspected resistant site at Rotoma (R1), 2) plants grown at Massey University from this original Rotoma seed (R2), and 3) a site near Taradale (T) where spraying is unlikely to have occurred for several years prior to collection. The seeds were grown in pots at Massey University and sprayed at the 4-5 leaf stage with several rates of MCPA. There was a significant difference in susceptibility between the three populations, as measured by scores, plant mortality and plant fresh weight. At the recommended application rate of $1.1 \mathrm{~kg} / \mathrm{ha}$, there was 0,33 and $90 \%$ mortality in the R1, R2 and T populations, respectively. 